\title{
Aplicação de filmes proteicos à base de soro de leite
}

\author{
Application of whey protein films
}

\author{
Cristiana Maria Pedroso YOSHIDA ${ }^{1 *}$, Aloísio José ANTUNES²
}

\section{Resumo}

A eficiência da aplicação de filmes à base de proteínas de soro de leite foi avaliada em um sistema de embalagem que consistia em um pote plástico utilizando-se filmes de proteínas de soro de leite como fechamento superior. Pedaços de maçã foram embalados e armazenados à temperatura ambiente $\left(25^{\circ} \mathrm{C}\right)$ e sob refrigeração $\left(10^{\circ} \mathrm{C}\right)$. Os filmes proteicos à base de soro de leite foram obtidos por três procedimentos distintos: por desnaturação térmica; com a incorporação de ácido esteárico (0,5\%, em massa); e por modificação enzimática utilizando-se a transglutaminase microbiana (10U/g proteína, ACTIVA TG-B ), a partir de uma formulação básica de 6,50\% de proteína, 3,0\% de plastificante (glicerol) e pH 7,0. A integridade dos filmes após embalagem e durante armazenamento foi observada, medindo-se as propriedades mecânicas dos filmes. A permeabilidade ao vapor d'água foi avaliada pela perda de massa, teor de umidade, e variação de textura dos pedaços de maçã. Os resultados indicaram que os filmes apresentam uma barreira moderada à umidade, apresentando diferença entre potes com e sem coberturas de filmes. A permeabilidade ao oxigênio foi conferida pelo escurecimento enzimático das maçãs pela ação da enzima polifenoxidase, apresentando diferença em relação ao das amostras acondicionadas em atmosfera modificada com gás $\mathrm{N}_{2}$.

Palavras-chave: soro de leite; filmes; embalagem; emulsionado; transglutaminase; atmosfera modificada.

\begin{abstract}
The efficiency of whey protein films packaging was evaluated. The packaging system consisted of whey protein films closing the top extremity of synthetic plastic container. Slices of apple were packed and stored at room temperature $\left(25^{\circ} \mathrm{C}\right)$ and at $10^{\circ} \mathrm{C}$. Modified atmosphere packaging (N2 gas flushing) was studied to verify the oxygen permeability of the films. Whey protein films (6.5\% of protein, $3.0 \%$ of glycerol, and pH 7.0) were obtained by thermal denaturation, emulsification $(0.5 \%(\mathrm{w} / \mathrm{w})$ with stearic acid), and enzymatic modification (10U/g protein of transglutaminase, ACTIVA-TG). Mechanical properties (tensile strength and elongation at break), water vapor permeability, and coloropacity properties of different films were evaluated. The film integrity was observed during the packaging and storage processing associated to the good mechanical properties. The water vapor permeability was evaluated by weight loss, moisture content, and texture profile of apple slices. The results showed that the whey protein films presented a moderated moisture barrier if compared with systems with no covering. The browning of the apple slices was investigated associated to the polyphenoloxidase action in presence of oxygen.

Keywords: whey protein; films; biodegradable packaging; emulsion film; transglutaminase; modified atmosphere.
\end{abstract}

\section{Introdução}

A embalagem deve preservar as características físicas, organolépticas, nutricionais e sanitárias dos alimentos durante o período de estocagem, transporte e comercialização. $\mathrm{O}$ desenvolvimento de embalagens comestíveis e biodegradáveis tem merecido atenção intensa dos pesquisadores durante as últimas décadas, que vêm estudando novos materiais provenientes de fontes renováveis como alternativa às embalagens plásticas sintéticas (THARANATHAN, 2003). Filmes e coberturas proteicas podem atuar como barreira semipermeável à umidade, gases e compostos aromáticos, controlando a transferência de massa (umidade, oxigênio, dióxido de carbono, lipídio) em sistemas alimentícios, mantendo a integridade estrutural e características de manuseio, retendo compostos aromáticos voláteis e servindo de veículos para aditivos (HERSHKO; NUSSINOVITCH, 1998). Os filmes proteicos podem ser utilizados como um complemento à embalagem sintética, prolongando a vida-de-prateleira garantindo maior qualidade do produto final, além de apresentar um potencial econômico, pois sua matéria-prima é de baixo custo e biodegradável (MCHUGH; SENESI, 2000; MATÉ; KROCHTA, 1998).

O soro de leite é um subproduto da indústria do queijo e da caseína, possui alto valor funcional e nutritivo e, devidamente processado, seja como concentrado ou isolado proteico, constitui-se num excelente ingrediente para a fabricação de vários alimentos industrializados. Uma quantidade substancial de soro de leite é descartada anualmente no Brasil, na forma de resíduo industrial, causando um grave problema ambiental. As proteínas do soro de leite têm sido utilizadas em diversas aplicações alimentícias, devido às suas propriedades funcionais, tais como, a gelatinização, emulsificação, solubilidade, formação de espuma, viscosidade, além do valor nutricional, sendo uma excelente fonte de aminoácidos essenciais (MORR; HA, 1993). Kim e Ustunol (2001) obtiveram bons resultados com filmes à

Recebido para publicação em 1/11/2007

Aceito para publicação em 3/1/2009 (002986)

${ }^{1}$ Faculdade de Engenharia Química, Universidade Estadual de Campinas - UNICAMP, CP 6066, CEP 13083-970, Campinas - SP, Brasil, E-mail: kity@feq.unicamp.br

2 Departamento de Alimentos e Nutrição, Faculdade de Engenharia de Alimentos, Universidade Estadual de Campinas - UNICAMP, CP 6121, CEP 13083-862, Campinas - SP, Brasil

${ }^{*}$ A quem a correspondência deve ser enviada 
base de isolado proteico de soro de leite, ressaltando a formação de filmes transparentes, o que favoreceu sua aplicação. Filmes obtidos a partir de proteínas de soro de leite caracterizam-se pela transparência, flexibilidade, ausência de odor e sabor, favorecendo sua aceitabilidade para consumo (CHEN, 1995).

A natureza hidrofílica dos filmes proteicos limita a sua aplicação em produtos que requerem barreira à umidade. A incorporação de lipídios (ceras e ácidos graxos) na matriz filmogênica proteica, reduz a afinidade por moléculas de água, reduzindo a permeabilidade ao vapor d'água dos filmes. McHugh e Krochta (1994) obtiveram filmes de proteínas do soro de leite ligadas à cera de abelha com menor permeabilidade ao vapor d'água; quando se aumentou a área superficial, pela diminuição do diâmetro das partículas lipídicas, foi obtida uma maior interação proteína-lipídio. Avena-Bustillos e Krochta (1993) obtiveram valores reduzidos de permeabilidade ao vapor d'água ao adicionar cera de abelha em filmes de caseinato de sódio. O mesmo resultado foi obtido por Sapru e Labuza (1994) em filmes à base de metilcelulose e ácido esteárico.

A modificação química ou enzimática em soluções proteicas favorece a incorporação de ligações inter e intramoleculares por ligações cruzadas. Estes procedimentos visam melhorar as propriedades físicas e de textura de produtos alimentícios, assim como propriedades funcionais de proteínas. A modificação enzimática é o processo mais aceitável devido ao seu caráter natural, não gerando produtos tóxicos por sua reação e apresentando uma alta especificidade (TROFIMOVA; DE JONGH, 2004; FÆRGMAND et al., 1998b). A modificação enzimática em proteínas pela catálise com transglutaminase não produz substâncias tóxicas, aromas indesejáveis ou perda significativa de nutrientes essenciais (FLANAGAN; GUNNING; FITZGERALD, 2003; DICKINSON, 1997).

A aplicação de filmes e coberturas em frutas e vegetais frescos ou minimamente processados reduz o amadurecimento, o escurecimento, a mudança de cor, a perda de aroma, umidade e textura, pois promove uma barreira a gases, vapor d'água, diminuindo as taxas de metabolismo e oxidação (LI; BARTH, 1998). Cobertura de alginato foi aplicada em cebolas, reduzindo a perda de água e aumentando o tempo de armazenamento (HERSHKO; NUSSINOVITCH, 1998). O mesmo resultado foi obtido em amostras de alho cobertas com filmes de alginato, gelana e carragena (NUSSINOVITCH; HERSHKO, 1996).

O metabolismo de alimentos minimamente processados continua ativo, aumentando a perecibilidade causada pela ruptura celular, aumentando a respiração, em consequência, reações provocam a mudança de cor, textura, aroma, desenvolvimento microbiano e produção de etileno. Diversas técnicas estão sendo desenvolvidas para reduzir a deterioração de alimentos minimamente processados, como a refrigeração, embalagem em atmosfera modificada, uso de aditivos e coberturas comestíveis (KING; BOLIN, 1989). Segundo Muratore et al. (2005), filmes com permeabilidade adequada podem ser usados para prevenir contaminação microbiana em alimentos frescos.

Diversas aplicações de filmes e coberturas biodegradáveis têm sido estudadas como alternativas para prolongar o tempo de armazenamento de produtos frescos e minimamente processados, tais como: emulsão de caseinato e ácido esteárico em cenouras descascadas (AVENA-BUSTILLOS; KROCHTA, 1993); coberturas de celulose em batatas e maçãs descascadas (BALDWIN et al., 1996); coberturas de celulose e óleo mineral em pimenta verde (LERDTHANANGKUL; KROCHTA, 1996); coberturas de cera de carnaúba e celulose em manga (BALDWIN et al., 1999); coberturas de proteínas de soro de leite em amendoim (MATÉ; KROCHTA, 1996). Entretanto, estudos envolvendo aplicação destes filmes na forma de embalagens são escassos na literatura especializada.

O objetivo deste estudo foi avaliar a eficiência de aplicação de diferentes tipos de filmes proteicos de soro de leite (filme padrão, filme emulsionado, filme modificado enzimaticamente) em um produto perecível (maçãs), analisando-se a integridade do produto (propriedades mecânicas) e propriedades de barreira (vapor d'água e oxigênio) pela perda de massa e de alterações na cor do produto embalado.

\section{Material e métodos}

\subsection{Materiais}

Os filmes foram obtidos a partir de concentrado proteico de soro de leite comercial, com $80 \%$ de proteína, fornecido pela indústria CALPRO Ingredients (Califórnia, USA). Também foi utilizado na formulação dos filmes, glicerol (MERCK) como plastificante, ácido esteárico (Riedel-de-Haën), enzima Transglutaminase (ACTIVA TG-MP, Ajinomoto Interamericana Ind. e Com. Ltda., hidróxido de sódio (Synth) e ácido acético (Synth). As enzimas utilizadas na digestibilidade foram pepsina (Sigma) e pancreatina (Sigma).

\subsection{Métodos}

\section{Filmes proteicos de soro de leite}

Os filmes proteicos de soro de leite foram obtidos por três procedimentos distintos, a saber: por desnaturação térmica, denominado filme padrão (FP); com a incorporação de um composto hidrofóbico, denominado filme emulsionado (FEM); e filme modificado enzimaticamente com transglutaminase (FTG).

\section{Filme padrão}

A proteína de soro de leite $(6,5 \%$, em massa) foi dispersa em água destilada, seguida de uma homogeneização até a solubilidade total. Após a solubilização, adicionou-se o plastificante $(3,0 \%$, em massa), sendo a solução filmogênica aquecida à temperatura de $90^{\circ} \mathrm{C}$ por 30 minutos em banho-maria (Mod TE 184 , Tecnal), com o objetivo de desnaturar a proteína. A solução foi resfriada em banho de gelo, sob agitação branda até atingir temperatura ambiente. $\mathrm{O}$ pH da solução foi ajustado para 7,0, utilizando-se hidróxido de sódio $0,1 \mathrm{~mol} . \mathrm{L}^{-1}$ ou ácido acético $0,1 \mathrm{~mol} . \mathrm{L}^{-1}$. A solução filmogênica foi dispersa em placas de Petri de plástico com diâmetro de $9 \mathrm{~cm}$. O controle de espessura foi efetuado por volume aplicado no suporte. A etapa seguinte correspondeu à evaporação do solvente, pelo processo de secagem nas condições 
de temperatura ambiente (aproximadamente entre 25 e $30^{\circ} \mathrm{C}$ ), por um período de 24 horas, garantindo uma secagem lenta dos filmes.

\section{Filme emulsionado}

Após a dispersão da proteína de soro de leite $(6,5 \%$, em massa) em água destilada, foi adicionado plastificante $(3,00 \%$ de glicerol) e a solução filmogênica foi aquecida à temperatura de $90{ }^{\circ} \mathrm{C}$ por 30 minutos em banho-maria (Mod TE 184, Tecnal). Imediatamente após esta etapa, adicionou-se ácido esteárico $(0,50 \%$, em massa). A solução foi homogeneizada em agitador mecânico (Fisatom, Mod. 713D), à velocidade de $4700 \mathrm{rpm}$ por 10 minutos, utilizando-se haste do tipo hélice, sob aquecimento por uma chapa quente (Hotlab II, Nalgon) $\left(\mathrm{T}=80^{\circ} \mathrm{C}\right)$ Resfriou-se a solução em banho de gelo até temperatura ambiente. As bolhas de ar foram retiradas utilizando-se bomba de vácuo. $\mathrm{O}$ pH da solução foi ajustado para 7,0, utilizando-se hidróxido de sódio 0,1 mol. $\mathrm{L}^{-1}$ ou ácido acético $0,1 \mathrm{~mol} \cdot \mathrm{L}^{-1}$. A solução filmogênica foi dispersa em placas de Petri de plástico com diâmetro de 9 e $14 \mathrm{~cm}$. O controle de espessura foi efetuado pelo volume aplicado no suporte.

\section{Filme modificado enzimaticamente}

A solução aquosa contendo 6,50\% de proteína do soro de leite e 3,0\% de plastificante (glicerol) foi preparada. Paralelamente, o produto (ACTIVA TG-MP) contendo a enzima foi solubilizado em água destilada, na concentração $10 \mathrm{U} / \mathrm{g}$ proteína. As duas soluções foram misturadas e ajustou-se o $\mathrm{pH}$ 7,0 com hidróxido de sódio $0,1 \mathrm{~mol} . \mathrm{L}^{-1}$ e ácido acético $0,1 \mathrm{~mol} \cdot \mathrm{L}^{-1}$. A incubação foi feita na temperatura de $50^{\circ} \mathrm{C}$, em banho-maria com agitação (Banho Dubnoff Mod. TE-053, Tecnal), por 180 minutos. Em seguida a enzima foi inativada pela imersão da solução filmogênica em banho-maria na temperatura de $85^{\circ} \mathrm{C}$, por 10 minutos. A solução foi resfriada em banho de água gelada até temperatura ambiente. A solução foi aplicada em placas de Petri com diâmetro de $9 \mathrm{~cm}$. A secagem foi feita em condições ambiente (aproximadamente 25 e $30^{\circ} \mathrm{C}$ ) por 24 horas.

\section{Sistemas de embalagem}

Maçãs argentinas foram adquiridas no mercado varejista, lavadas por imersão em solução de hipoclorito de sódio, secas e cortadas na forma de cilindros de dimensões de $4,0 \mathrm{~cm}$ de diâmetro e $1,5 \mathrm{~cm}$ de espessura.

Os sistemas de embalagem constituíram-se em potes plásticos, contendo pedaços de maçã, fechados com filmes proteicos de soro de leite. Os sistemas estudados foram: aberto (pote + maçã); sistemas fechados (pote + maçã + filme), com e sem a injeção de gás nitrogênio. Após o corte, as maçãs foram imediatamente colocadas nos potes plásticos, que foram fechados com os filmes proteicos de soro de leite, utilizando-se cola de silicone; este tratamento foi denominado sistema fechado com ar ambiente. Em embalagens com atmosfera modificada, após o fechamento, gás nitrogênio analítico era injetado por 1 minuto, visando expulsar todo o ar ambiente de dentro dos potes plásticos. A condição controle foi estipulada como cilindros de maçã em potes sem o fechamento (sistema aberto). Todos os experimentos foram feitos em triplicata.

As embalagens foram armazenadas em duas condições, na temperatura de $25^{\circ} \mathrm{C}$ e $75 \%$ de umidade relativa e em $10{ }^{\circ} \mathrm{C}$, em incubadoras BOD (TECNAL, Mod. TE-390). A barreira ao vapor d'água e ao oxigênio foi avaliada pela determinação da variação de massa do sistema, do perfil de textura da maçã, do teor de umidade da maçã e da variação dos parâmetros de cor da maçã. A perda de massa foi feita por pesagens periódicas dos sistemas de embalagem em balança analítica (intervalos de 24 horas) durante 72 horas. A textura foi medida utilizando-se um texturômetro TATX2, avaliando-se a força necessária para perfurar os pedaços de maçã, utilizando-se um probe de 2,0 $\mathrm{mm}$ de diâmetro, na velocidade de $1 \mathrm{~mm} / \mathrm{s}$. E o teor de umidade final dos pedaços de maçã foi determinado por diferença de massa em estufa por 24 horas a $60^{\circ} \mathrm{C}$, seguido por 12 horas a $105^{\circ} \mathrm{C}$. A avaliação das alterações de cor $\left(a^{*}, b^{*}\right.$ e $\left.L^{*}\right)$ foi realizada utilizando-se um colorímetro Hunterlab (Colorquest II, Hunter Associates Laboratory Inc, Virginia).

\subsection{Caracterização dos filmes}

Avaliação da cor

A cor final dos filmes foi medida em colorímetro (Colorquest II, Hunter Associates Laboratory Inc, Virginia) verificando-se os valores do índice de luminosidade $\mathrm{L}^{\star}$, índices de croma $\mathrm{a}^{\star} \mathrm{e} \mathrm{b}^{\star}$ e a opacidade.

\section{Teor de umidade}

O teor de umidade dos filmes foi medido pela porcentagem da perda de massa após a secagem em uma estufa à temperatura de $110^{\circ} \mathrm{C}$ por 24 horas (MAHMOUD; SAVELLO, 1992).

\section{Solubilidade proteica}

Em um tubo de ensaio adicionou-se uma quantidade de filme conhecida, correspondente à $0,1 \mathrm{~g}$ de proteína, em tampão Mcllvaine ( $\mathrm{pH} 7,0$ ), a solução foi misturada em um Vórtex por 1 minuto, e deixada em repouso por 48 horas, sendo novamente agitada em Vórtex por 1 minuto. A solução foi filtrada e a quantidade de proteína solubilizada no sobrenadante foi determinada pelo Método de Kjeldhal (AOAC, 1996).

\section{Permeabilidade ao vapor d’água}

A permeabilidade ao vapor d'água foi determinada baseando-se no método padronizado ASTM E96-95 (1995), que corresponde à técnica gravimétrica, no qual os filmes foram fixados na parte superior de uma célula ou recipiente que contém um dessecante (sílica). Este sistema foi acondicionado em uma câmara com temperatura e umidade relativa controladas (solução de cloreto de sódio saturada, com umidade relativa correspondente a 75\%). A medida do peso final do sistema foi feita após 5 dias de incubação do sistema. A determinação foi feita utilizando-se 5 amostras de cada ensaio. 


\section{Propriedades mecânicas}

A determinação da tração na ruptura e porcentagem de elongação foi feita, baseando-se no método padronizado ASTM D882 (ASTM, 1995). As amostras foram cortadas $(25,4 \times 100,0 \mathrm{~mm})$ e acondicionadas em câmaras com temperatura $\left(25^{\circ} \mathrm{C}\right)$ e umidade relativa $(75 \%)$ controladas, num período de 48 horas. Em seguida, a tração na ruptura e a porcentagem de elongação foram medidas utilizando-se o texturômetro TATX2. A tração na ruptura foi calculada dividindo-se a força pela área de secção transversal e a porcentagem de elongação, dividindose a distância obtida pela distância inicial do probe $(50 \mathrm{~mm})$ e multiplicando-se por 100. A determinação foi feita utilizando-se 10 amostras de cada ensaio.

\section{Digestibilidade proteica}

A digestibilidade in vitro foi determinada de acordo com Akeson e Stahmann (1964). As amostras de filme contendo 0,1g de proteína foram pesadas e hidrolisadas com a enzima pepsina em solução de ácido clorídrico 0,1 mol.L ${ }^{-1}$, por 4 horas a $37^{\circ} \mathrm{C}$, em banho-maria sob agitação lenta. Ajustou-se o pH para 7,0, e, então as amostras foram hidrolisadas com a enzima pancreatina em solução de tampão fosfato $\mathrm{pH} 8,0$, por 24 horas a $37^{\circ} \mathrm{C}$ e, em banho-maria sob agitação lenta. Em seguida, as proteínas não hidrolisadas foram precipitadas com TCA (ácido tricloroacético), a solução foi centrifugada por 15 minutos a $5000 \mathrm{rpm}$ e filtrada em papel de filtro. O teor de nitrogênio solúvel na solução sobrenadante foi determinada pelo Método de Kjeldhal (AOAC, 1996).

\section{Análise estatística}

A análise estatística dos resultados foi efetuada pelo teste de Tukey com diferença significativa de $p \leq 0,05$, utilizandose o programa computacional SAS (SAS Institute Inc., Cory, N.C., USA).

\section{Resultados e discussão}

\subsection{Caracterização dos filmes proteicos de soro de leite}

A aplicação dos filmes consistiu em comparar os resultados finais das principais propriedades (permeabilidade ao vapor d'água, tensão na ruptura e porcentagem de elongação) em uma situação real. A Tabela 1 resume as características finais dos filmes proteicos obtidos por: desnaturação térmica, filme padrão (FP); com incorporação de um composto hidrofóbico - filme emulsionado (FEM) contendo $0,5 \%$ de ácido esteárico; e por modificação enzimática, filme catalisado com transglutaminase
(FTG) na concentração de $10 \mathrm{U} / g$ proteína, incubado por 180 minutos.

O aspecto visual está relacionado com a cor e transparência final dos filmes proteicos e foi avaliado pela variação de cor e opacidade entre os três tipos de filme, sendo $\mathrm{L}^{*} \mathrm{o}$ índice de luminosidade, variando de branco $\left(-\mathrm{L}^{*}\right)$ para preto $\left(-\mathrm{L}^{\star}\right)$; $\mathrm{a}^{\star} \mathrm{o}$ índice de croma com as coordenadas de verde $\left(-\mathrm{a}^{\star}\right)$ para vermelho $\left(+\mathrm{a}^{\star}\right), \mathrm{b}^{\star} \mathrm{o}$ índice de croma com as coordenadas de azul $\left(-\mathrm{b}^{\star}\right)$ para amarelo $\left(+b^{\star}\right)$; e $\Delta \mathrm{E}$ a diferença total de cor dos filmes em relação ao filme padrão. A Tabela 2 apresenta os parâmetros de cor, opacidade e a diferença total de cor determinados e calculados para os filmes padrão (FP), filme emulsionado (FEM) e filme catalisado pela transglutaminase (FTG).

Filmes emulsionados apresentaram uma diferença total de cor $(\Delta \mathrm{E})$ mais acentuada em relação ao filme padrão, relacionada à incorporação de lipídio, que promoveu um aumento na opacidade e no parâmetro $b^{*}$, e uma redução na luminosidade e do parâmetro $\mathrm{a}^{\star}$. Quanto aos filmes modificados enzimaticamente, as características de cor e opacidade foram similares às encontradas no filme padrão.

A opacidade é uma propriedade de grande importância na aplicação dos filmes como embalagem alimentícia e está associada à morfologia não homogênea da matriz filmogênica emulsionada, na qual partículas lipídicas provocam uma luz visível que dispersa através do filme, causando a opacidade.

Ozdemir e Floros (2008) observaram um aumento na opacidade de filmes proteicos de soro de leite com adição de cera de abelha. Kim e Ustunol (2001) também obtiveram filmes de isolado proteico de soro de leite com maior opacidade quando se incorporou cera de candelila na formulação, assim como McHugh e Krochta (1994) em filmes emulsionados de proteína de soro com diferentes tipos de ácidos graxos (ácido láurico, palmítico, esteárico e mirístico). Yang e Paulson (2000) observaram um aumento na opacidade de filmes de gelana proporcional à concentração de ácido esteárico-palmítico adicionada. E Gallo et al. (2000) concluíram que filmes emulsionados de metilcelulose eram cinco vezes menos transparentes que os filmes controle (somente metilcelulose).

\subsection{Digestibilidade proteica}

A digestibilidade proteica dos filmes de soro de leite foi estudada, visando averiguar a disponibilidade biológica e a possibilidade de ser uma embalagem comestível. A metodologia in vitro agiliza os resultados de disponibilidade biológica e expressa a concentração de nitrogênio solúvel em relação com a concentração total de nitrogênio da amostra. $O$ valor encontrado

Tabela 1. Solubilidade protéica (SP), permeabilidade ao vapor d'água (TPVA), tração na ruptura (TS) e elongação (E) dos filmes à base de soro de leite: padrão (FP), emulsionado (FEM) e modificado enzimaticamente (FTG).

\begin{tabular}{lcccc}
\hline Tipo de filme & SP $(\%)$ & TPVA $\left(\mathrm{gmm} / \mathrm{hm}^{2} \mathrm{kPa}\right)$ & TS $(\mathrm{MPa})$ & E $(\%)$ \\
\hline FP & $0,7415 \pm 0,0165$ & $0,3023 \pm 0,0134$ & $2,5558 \pm 0,1983$ & $68,04 \pm 5,23$ \\
FEM & $0,7025 \pm 0,0001$ & $0,2680 \pm 0,0006$ & $2,2500 \pm 0,0100$ & $44,80 \pm 0,28$ \\
FTG & $0,9041 \pm 0,0245$ & $0,2705 \pm 0,0057$ & $3,0752 \pm 0,3201$ & $72,52 \pm 0,62$ \\
\hline
\end{tabular}


Tabela 2. Parâmetros de cor $\left(\mathrm{L}^{*}, \mathrm{a}^{*}, \mathrm{~b}^{*}\right)$, diferença total de cor $(\Delta \mathrm{E})$ e opacidade dos filmes de soro de leite: padrão (FP), filme emulsionado (FEM) e filme catalisado pela transglutaminase (FTG).

\begin{tabular}{lccccc}
\hline \multicolumn{1}{c}{ Tipo de Filme } & \multicolumn{1}{c}{$\mathrm{L}^{*}$} & $\mathrm{a}^{*}$ & $\mathrm{~b}^{*}$ & Opacidade & $\Delta \mathrm{E}$ \\
\hline FP & $84,62 \pm 0,17^{\mathrm{a}}$ & $-0,91 \pm 0,02^{\mathrm{b}}$ & $10,52 \pm 0,50^{\mathrm{e}}$ & $19,99 \pm 0,15^{\mathrm{g}}$ & - \\
FEM & $83,68 \pm 0,35^{\mathrm{a}}$ & $-0,68 \pm 0,02^{\mathrm{c}}$ & $18,54 \pm 0,81^{\mathrm{f}}$ & $31,27 \pm 0,62^{\mathrm{h}}$ & 8,08 \\
FTG & $85,26 \pm 0,23^{\mathrm{a}}$ & $-0,98 \pm 0,04^{\mathrm{d}}$ & $10,17 \pm 0,57^{\mathrm{e}}$ & $19,71 \pm 0,40^{\mathrm{g}}$ & 0,73 \\
\hline
\end{tabular}

$\mathrm{a}, \mathrm{b}, \mathrm{c}, \mathrm{d}, \mathrm{e}, \mathrm{f}, \mathrm{g}, \mathrm{h}=$ diferenças significativas entre as médias $(\mathrm{p}<0,05)$ calculadas através do método de Tukey pelo programa computacional SAS $($ SAS Institute Inc., Cary, N.C., USA).

para filme proteico de soro de leite, com a formulação padrão foi de 93,97\%; para filmes emulsionados, de 92,55\%; e para filmes modificados enzimaticamente, de $89,88 \%$, concluindo-se que todos os filmes apresentaram digestibilidade elevada.

\subsection{Análise dos sistemas de embalagem}

Diferentes sistemas de aplicação foram testados para avaliar a eficiência dos filmes proteicos de soro de leite como embalagens de produtos alimentícios. A seleção do modo de aplicação foi baseada nas características finais dos filmes (propriedades de barreira e mecânicas), ou seja, o objetivo foi constatar estas propriedades pelo comportamento prático como embalagem em alimentos. Ensaios preliminares foram realizados aplicando-se os filmes proteicos de diferentes maneiras: à embalagem (filme) selada a quente, coberturas proteicas (recobrimento das amostras) e ao fechamento de um recipiente. A selagem em filmes proteicos à base de soro de leite não se manteve durante o processo, observando-se que, em alta umidade relativa (75\%), os filmes adsorviam umidade e tendiam a abrir os pontos de selagem, não garantindo a transferência de vapor d'água somente através das paredes da embalagem. Quanto à técnica de recobrimento, variações na perda de massa e teor de umidade, na mudança de cor e textura foram averiguadas, mas as diferenças não foram estatisticamente significativas para os produtos alimentícios estudados.

A aplicação dos filmes como fechamento de um recipiente permitiu avaliar as principais propriedades dos filmes proteicos à base de soro de leite. Os filmes foram aplicados fechando-se um recipiente plástico contendo cilindros de maçã, garantindo-se que a transferência de massa ocorresse somente através da superfície filmogênica. O sistema pode ser visualizado na Figura 1.

A perda de umidade em maçãs cortadas provoca o encolhimento e alterações na textura (crocância). A maçã é um fruto que, após o corte, fica sujeito à ação da enzima polifenoxidase e, na presença de oxigênio, promove um escurecimento. Alimentos minimamente processados devem manter a consistência, aparência fresca, cor aceitável e ser razoavelmente livres de defeitos. A avaliação visual é o fator de maior efeito na escolha de compra do consumidor, seguido da firmeza no toque, estando diretamente relacionados com a mudança de cor e perda ou ganho de umidade (SHEWFELT, 1987).

A propriedade de barreira ao vapor d'água dos filmes proteicos foi avaliada pela perda de massa, teor de umidade e variação na textura das maçãs em função do tempo de armazenamento. As propriedades mecânicas (tensão na ruptura e porcentagem de

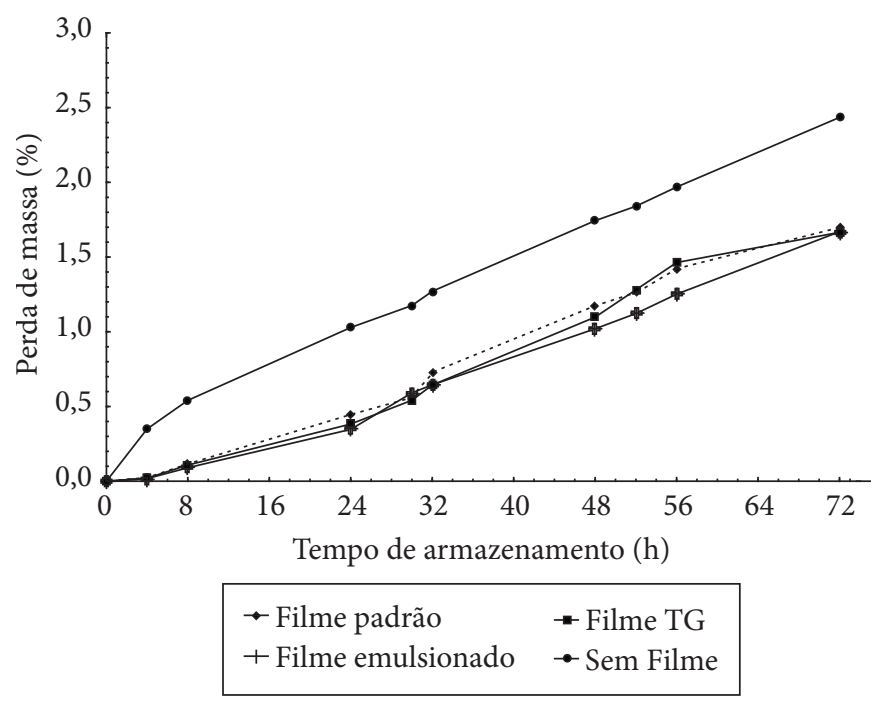

Figura 1. Sistema de embalagem fechado com filmes proteicos de soro de leite contendo cilindros de maçã.

elongação) foram requeridas durante a aplicação dos filmes nos potes, pois a fragilidade não permitiu a total vedação do pote plástico, apresentando pontos de falhas, quebra. E a propriedade de barreira a gases foi controlada pelo escurecimento enzimático dos pedaços de maçã, na presença de oxigênio, medida pela mudança nos parâmetros de cor.

É importante ressaltar que neste estudo não houve uma preocupação em determinar condições de armazenamento para a vida de prateleira de maçãs em pedaços, sendo que a escolha deste produto foi baseada na rápida deterioração (perda de umidade e escurecimento enzimático), o que permitiu a avaliação dos filmes atuando como barreira à umidade e a gases, mantendo sua integridade durante o tempo de armazenamento.

No armazenamento a $\mathrm{T}=25^{\circ} \mathrm{C}$, o comportamento das maçãs em sistema fechado com e sem a injeção de nitrogênio foi similar, assim as curvas representadas a seguir correspondem à média das duas medidas. A perda de massa das amostras de maçã em sistemas aberto e fechado com filme padrão (FP), emulsionado (FEM) e modificado enzimaticamente com transglutaminase (FTG) em função do tempo de armazenamento, pode ser avaliada na Figura 2.

Os filmes proteicos atuaram como barreira à umidade quando comparados com o sistema aberto, não apresentando diferença significativa entre os diferentes filmes, mas observou-se que 


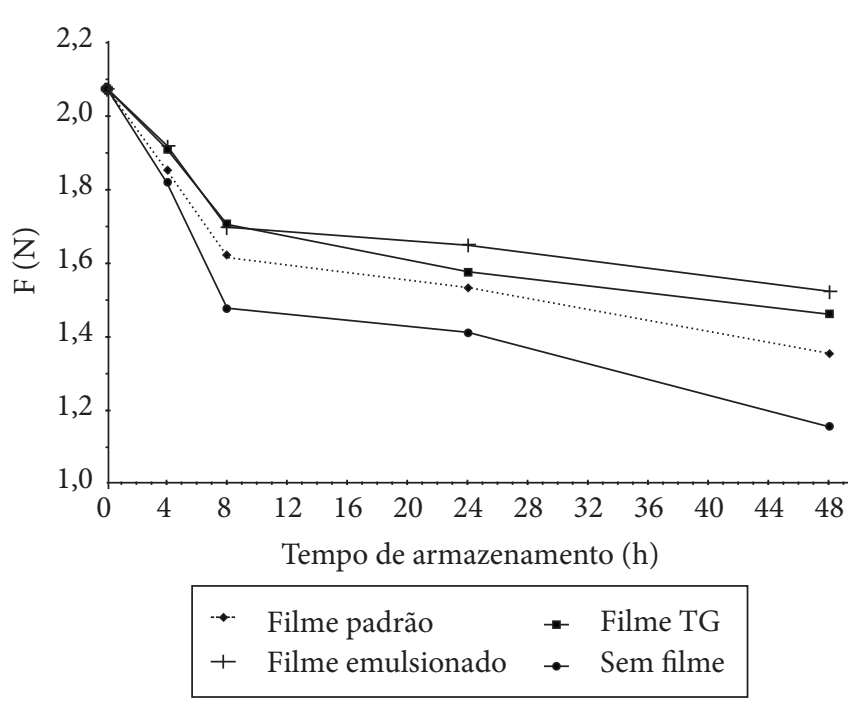

Figura 2. Perda de massa das amostras de maçã acondicionadas a $25^{\circ} \mathrm{C}$ e $75 \%$ de umidade relativa em sistema aberto e fechado com filmes proteicos de soro de leite: padrão, emulsionado e modificado enzimaticamente.

filmes emulsionados tenderam a perder menos umidade que filmes padrão, quando associados à presença de um composto hidrofóbico na matriz filmogênica, que reduz a permeabilidade ao vapor d'água dos filmes.

A perda de massa dos pedaços de maçã foi gradual em todos os sistemas de embalagem, resultando em uma perda de 2,43\% após 72 horas de acondicionamento em sistema aberto; e em sistema fechado, os comportamentos com diferentes tipos de filmes foram muito similares, com uma perda de massa média de $1,68 \%$, no mesmo período, não existindo diferença significativa entre os resultados no mesmo tempo de armazenamento. Quanto à transferência de umidade, os sistemas de embalagem fechada com os filmes proteicos de soro de leite aumentaram o tempo de armazenamento das maçãs cortadas, ou seja, a perda de massa em sistema aberto $(t=72$ horas) equivalente à perda de massa final em sistema fechado foi atingida após 48 horas de armazenamento.

Esta tendência da perda de massa gradual e contínua foi observada em pimentões recobertos com película de fécula de mandioca na ordem de $1,03 \%$, e sem cobertura, 1,15\% após 12 dias de armazenamento (VICENTINI et al., 1999). Em cebolas frescas, a perda de massa foi de aproximadamente $2,80 \%$ após estocagem a $23^{\circ} \mathrm{C}$ e $70 \%$ de umidade relativa por 15 dias, e com cobertura de alginato foi de 1,80\% (HERSHKO; NUSSINOVITCH, 1998).

O teor de umidade final das maçãs após o tempo de armazenamento confirmou os resultados das curvas de perda de massa. A diferença no teor de umidade das maçãs acondicionadas em sistema fechado em função do tempo foi significativa somente após 48 horas de armazenamento, apresentando um valor médio de $85,46 \%$. Este teor de umidade foi atingido em sistema aberto após 8 horas, indicando que a aplicação dos filmes retardou a perda no teor de umidade. O teor de umidade inicial das maçãs é muito alto, e qualquer perda de água provoca alterações que as tornam não aceitáveis para o consumo, sendo a textura uma das propriedades alteradas. Os resultados deste parâmetro, representados pela força necessária para perfurar as amostras de maçã, podem ser avaliados na Figura 3, observando-se a perda de textura em função do tempo de armazenamento após o corte.

Os filmes emulsionados (FEM) e modificados com a transglutaminase (FTG) mantiveram a textura das maçãs próxima à condição inicial por um período de tempo maior que o filme padrão, confirmando os resultados de permeabilidade ao vapor, sendo $0,2680 \mathrm{gmm} / \mathrm{hm}^{2} \mathrm{kPa}$, para filmes emulsionados, seguidos de $0,2705 \mathrm{gmm} / \mathrm{hm}^{2} \mathrm{kPa}$, para modificado com transglutaminase, e $0,3028 \mathrm{gmm} / \mathrm{hm}^{2} \mathrm{kPa}$, para filmes padrão. Em sistema aberto (sem filme), a força requerida para perfurar o pedaço de maçã foi menor do que em sistemas fechados. $\mathrm{O}$ valor atingido em 48 horas de armazenamento em sistema fechado foi equivalente a 8 horas em sistema aberto, indicando um prolongamento no tempo de armazenamento em 40 horas, quanto à barreira a oxigênio. Isto relata o aspecto visual final das amostras acondicionadas em sistema aberto, que se apresentavam em processo de deterioração, com redução do tamanho (encolhimento no diâmetro e altura).

A mudança de cor nas amostras de maçã está diretamente relacionada com a enzima polifenoxidase, que age somente na presença de oxigênio, oxidando compostos fenólicos. Filmes poliméricos apresentam barreira a gases, devido à estrutura da rede filmogênica ser fechada e ordenada por pontes de hidrogênio (YANG; PAULSON, 2000). Esta propriedade foi avaliada pela determinação dos parâmetros de cor nos pedaços de maçã em função do tempo de armazenamento nas condições de $25{ }^{\circ} \mathrm{C}$ e $75 \%$ de umidade relativa, em sistema aberto (sem filme) e sistema fechado com diferentes tipos de filmes, com e sem a injeção de gás nitrogênio.

O índice de luminosidade das amostras de maçã diminuiu nas primeiras 4 horas de armazenamento, mantendo-se constante durante o armazenamento, ou seja, as maçãs tenderam a escurecer em sistemas aberto e fechado, com e sem a injeção de nitrogênio. As pequenas variações encontradas nos resultados iniciais $(\mathrm{t}=0$ horas) podem estar associadas a diferentes estágios de maturação, possíveis defeitos causados por "batidas", fissuras, que aceleram o processo deteriorativo, mas não impediram a análise da tendência dos parâmetros de cor em função do tempo de armazenamento.

O índice de croma a ${ }^{\star}$ representa a mudança da cor de verde (valores negativos) para o vermelho (valores positivos), sendo que este parâmetro está relacionado com o escurecimento enzimático que ocorre em maçãs. Segundo Baldwin et al. (1996), quanto maior $\mathrm{a}^{*}$, maior o escurecimento das amostras. $\mathrm{O}$ escurecimento evidencia a ação da polifenoxidase, que resulta na redução da qualidade visual, em mudanças no aroma e perda de nutrientes (MCHUGH; SENESI, 2000). A Tabela 3 apresenta os dados de $\mathrm{a}^{*}$ em função do tempo de armazenamento.

$\mathrm{O}$ aumento no valor de $\mathrm{a}^{*}$ indicou a ocorrência do escurecimento enzimático nos pedaços de maçã durante a estocagem, com 
Tabela 3. Índice de croma ( $\mathrm{a}^{*} \pm$ desvio padrão) das amostras de maçã acondicionadas em sistema aberto e fechado com filmes protéicos de soro de leite (padrão (FP), emulsionado (FEM) e modificado enzimaticamente (FTG)) com $\left(\mathrm{N}_{2}\right)$ e sem (ar) a injeção do gás nitrogênio, na $\mathrm{T}=25^{\circ} \mathrm{C}$ e UR $=75 \%$.

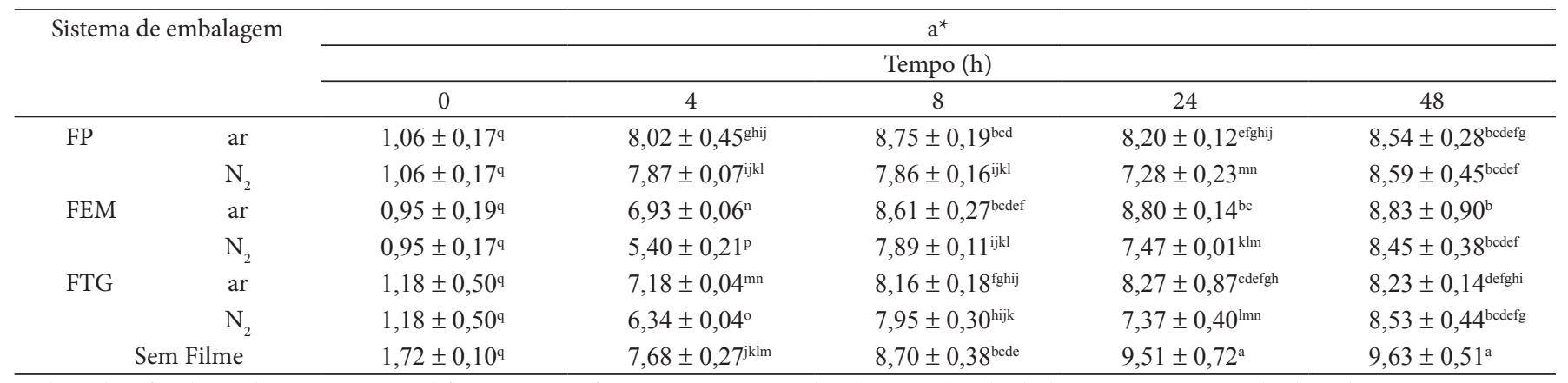

a, b, c, d, e, f, g, h, i, j, l, m, n, o, p, q - diferenças significativas entre as médias $(\mathrm{p}<0,05)$ calculadas através do método de Tukey pelo programa computacional SAS (SAS Institute Inc., Cary, N.C., USA).

comportamento similar em sistema aberto e fechado, tendendo à coloração vermelha, observando-se uma diferença estatisticamente significativa nas amostras acondicionadas com a injeção de $\mathrm{N}_{2}$ que apresentaram valores menores de $\mathrm{a}^{*}$ em relação aos potes fechados com ar ambiente. Em todoas os sistemas trabalhados, o valor do parâmetro $\mathrm{a}^{*}$ aumentou até 8 horas de armazenamento, podendo associar-se a uma concentração inicial de oxigênio dentro dos potes, suficiente para promover o escurecimento, devendo ressaltar-se que, durante o corte, já estava ocorrendo a ação da enzima.

Em sistema aberto, após 24 horas de armazenamento, o índice de croma $\mathrm{a}^{*}$ apresentou valores maiores. Neste caso as maçãs estavam em contato direto com o ar ambiente, ou seja, maior concentração de oxigênio, que promoveu maior escurecimento quando comparados com as amostras em sistemas fechados, e a injeção de nitrogênio diminuiu o valor do parâmetro $\mathrm{a}^{*}$. Pode-se concluir que as embalagens proteicas atuaram com uma barreira moderada ao oxigênio, e a atmosfera modificada é uma alternativa para retardar o escurecimento enzimático em maçãs. Maté e Krochta (1996b) concluíram que coberturas de isolado protéico de soro de leite diminuíram a concentração de oxigênio em amendoins, retardando o processo de rancidez. O mesmo foi observado quanto à redução de oxidação lipídica em amendoins cobertos por filmes de isolado proteico de soro de leite e armazenados a $23^{\circ} \mathrm{C}$. (MIN; KROCHTA, 2007). A composição atmosférica da embalagem foi o fator que mais influenciou a atividade da polifenoxidase em maçãs cortadas armazenadas em sacos plásticos (SOLIVA-FORTUNY et al., 2001).

O valor de a* encontrado em 48 horas nas maçãs acondicionadas em sistema fechado foi atingido em 8 horas em sistema aberto, indicando que o filme atuou como barreira ao oxigênio, prolongando o tempo de armazenamento. A aplicação de atmosfera modificada $\left(\mathrm{N}_{2}\right)$ retardou o escurecimento em relação a sistemas somente fechados. Filmes emulsionados e modificados com a transglutaminase apresentaram diferenças na barreira ao oxigênio até 24 horas de armazenamento, quando comparados com o filme padrão e sistema aberto, ou seja, a presença do ácido graxo nesta concentração $(0,50 \%)$ na formulação filmogênica não favoreceu a permeabilidade ao oxigênio, que é uma característica de filmes

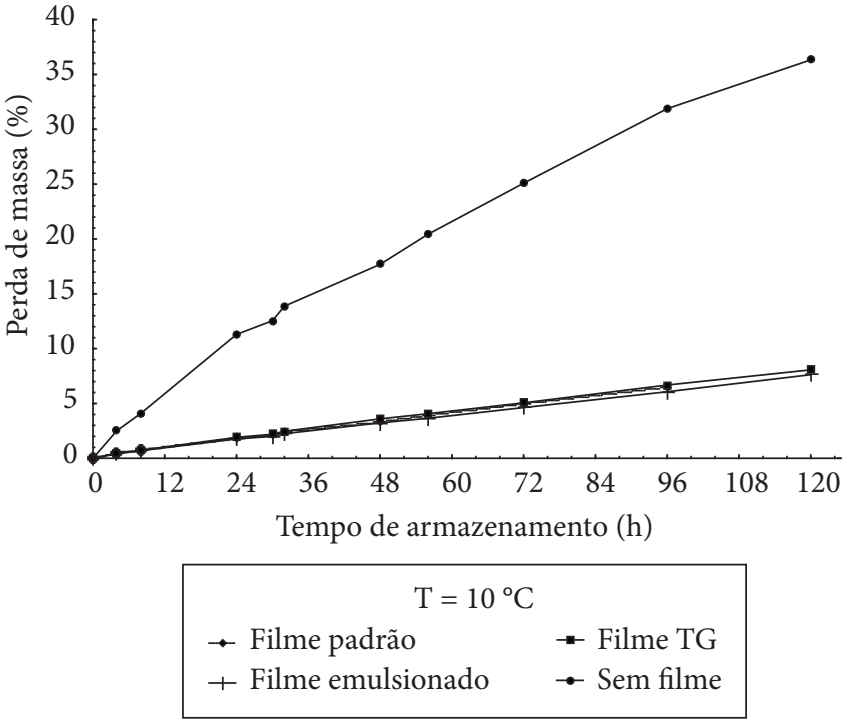

Figura 3. Perfil de textura das amostras de maçã acondicionadas em sistema aberto e fechado com filmes proteicos de soro de leite (padrão, emulsionado e modificado enzimaticamente) em função do tempo de armazenamento.

hidrofóbicos, a baixa barreira a gases. McHugh e Senesi (2000) também não constataram efeito significativo na adição de lipídio em coberturas à base de purê de maçã em pedaços de maçã, apesar de apresentarem valores menores de permeabilidade ao vapor d’água em relação ao filme controle.

As maçãs tenderam a uma coloração amarela mais forte $\left(\right.$ maior $\left.\mathrm{b}^{*}\right)$ em todas as condições trabalhadas, mas este índice não apresentou relação representativa da mudança de cor entre os diferentes sistemas de embalagem em função do tempo de armazenamento, nem com as embalagens com atmosfera modificada.

Baldwin et al. (1996) avaliaram a mudança de cor em pedaços de maçã acondicionadas em sacos plásticos à temperatura 
ambiente, observando o aumento nos índices de croma $\mathrm{a}^{*} \mathrm{e} \mathrm{b}^{*}$ e a diminuição na luminosidade $\mathrm{L}^{*}$, sendo que representaram a porcentagem de inibição do escurecimento pela variação no parâmetro $a^{*}$. Pedaços de carne fresca embalados em filmes biodegradáveis não apresentaram diferença significativa nos parâmetros de cor durante o armazenamento a 4 e $15^{\circ} \mathrm{C}$ (CANNARSI et al., 2005).

\subsection{Armazenamento a frio}

O consumo de alimentos minimamente processados vem aumentando, devido ao crescimento da procura de produtos mais saudáveis, naturais e com maior praticidade. Manter a qualidade destes produtos é um fator importante e crítico, pois o tempo de armazenamento é curto. Alternativas têm sido expostas, sendo que filmes proteicos podem ser considerados uma delas, como um complemento à embalagem sintética.

Alimentos minimamente processados são armazenados geralmente em temperaturas mais baixas, que previnem o desenvolvimento microbiano e reduzem a taxa de respiração celular, retardando o apodrecimento. As amostras de maçã foram armazenadas na temperatura de $10^{\circ} \mathrm{C}$, simulando a condição da geladeira, aproximando-se da situação real cotidiana. A umidade relativa de uma geladeira não é controlada e depende do tipo de produto armazenado, que troca umidade com o ar ambiente até o equilíbrio. Desta forma, esta variável foi medida durante o tempo de acondicionamento, somente para controle do processo, apresentando um valor médio de $73 \%$.

A perda de massa das amostras de maçã em função do tempo de acondicionamento em sistema aberto (sem filme) e sistema fechado com filme padrão (FP), filme emulsionado (FEM) e modificado enzimaticamente com transglutaminase (FTG) pode ser analisada na Figura 4. Novamente, o comportamento das maçãs armazenadas em sistema fechado com e sem a injeção de nitrogênio foi similar, sendo então apresentada a média dos resultados obtidos para cada tipo de filme.

A perda de massa aumentou gradualmente em função do tempo (Figura 4), sendo mais acentuada em maçãs acondicionadas em sistema aberto e, em sistema fechado, não foi observada diferença significativa entre os diferentes tipos de filme para cada tempo. A perda de massa atingida em 96 horas em sistema aberto foi de $31,88 \%$ e em sistema fechado, de 6,53\% com filme padrão, de 6,07\% com filme emulsionado e de 6,69\% com filme modificado enzimaticamente. Em sistema aberto, a perda de massa equivalente à condição final em sistema fechado ( $t=96$ horas $)$ foi atingida em aproximadamente 13 horas de acondicionamento, indicando um prolongamento no tempo de armazenamento, em termos de migração de umidade sob refrigeração, como consequência da propriedade de barreira a vapor d'água dos filmes proteicos de soro de leite.

O teor de umidade das maçãs após o acondicionamento confirmou os resultados de perda de massa: as acondicionadas em sistema aberto apresentaram maior redução no teor de umidade e as em sistema fechado com os diferentes tipos de filmes, não apresentaram diferença significativa entre si, podendo-se ressaltar que somente filmes emulsionados apresentaram o maior teor de umidade em relação a todas as condições trabalhadas. A diferença no teor de umidade não foi significativa durante o armazenamento em sistema fechado, mas a mínima perda de água em pedaços de maçã fresca provoca alterações marcantes no aspecto físico e visual. No final do experimento, as amostras de maçã haviam encolhido (reduziram o diâmetro e espessura), enrugado e amolecido, principalmente as acondicionadas em sistema aberto.

A perda de umidade em alimentos com alto teor de umidade, como a maçã, tende a perder a suculência e a frescura (SZCZESNIAK, 1998). A textura das maçãs seguiu a mesma tendência acima descrita para a perda de massa e teor de umidade, decresceu com o tempo de armazenamento, necessitando uma menor força de perfuração, ou seja, afastando-se da condição de fruta fresca. Os resultados da redução de textura, a $10^{\circ} \mathrm{C} \mathrm{em}$ sistema aberto (sem filme) e sistema fechado com diferentes tipos de filme, podem ser analisados na Figura 5 .

Até 4 horas de armazenamento, somente as amostras fechadas com os filmes emulsionados mantiveram a textura próxima à inicial, evidenciando uma menor permeabilidade ao vapor d’água de filmes contendo lipídio. Após este período, em todos os tratamentos, houve redução da força de perfuração, confirmando o aspecto visual de maçãs com menores tamanhos e secos. Em $\mathrm{t}=96$ horas, as maçãs acondicionadas em sistema fechado apresentaram uma textura similar à atingida em 48 horas em sistema aberto, indicando que a aplicação de filmes proteicos aumentou o tempo de armazenamento a $10^{\circ} \mathrm{C}$.

A redução do tamanho dos pedaços de maçã foi visualmente perceptível, principalmente as acondicionadas em sistema aberto, confirmando os resultados obtidos quanto à perda de umidade. É importante ressaltar que neste estudo não houve a preocupação em definir condições ótimas de armazenamento do produto, ou seja, que mantivessem as características das maçãs aceitáveis para o consumo, e sim avaliar as propriedades dos filmes proteicos de soro de leite, determinando sua atuação como barreira à umidade e gases, observando sua integridade durante todo o período de armazenamento (ausência de fraturas, fissuras). Desta forma, pode-se concluir que os filmes proteicos atuaram como uma barreira moderada à umidade em armazenamento a frio $\left(10^{\circ} \mathrm{C}\right)$.

A avaliação da permeabilidade a gases dos filmes na temperatura de $10{ }^{\circ} \mathrm{C}$ foi efetuada, baseando-se na variação de cor dos pedaços de maçã, medida pela luminosidade e índice de croma $a^{\star} \mathrm{eb}^{\star}$.

As maçãs após o corte tenderam a escurecer, reduzindo a luminosidade quando armazenadas em sistema aberto e fechado, diminuindo até 8 horas de armazenamento, mantendo-se constante após este período. A injeção de nitrogênio dentro das embalagens manteve uma maior luminosidade dos pedaços de maçã quando comparadas com as acondicionadas em embalagens fechadas sem injeção de nitrogênio. O mesmo resultado foi observado por Soliva-Fortuny et al. (2001) em maçãs armazenadas sob refrigeração em sacos plásticos em atmosfera modificada com nitrogênio, apresentando um decréscimo exponencial de $\mathrm{L}^{*}$ durante o armazenamento, de 83,20 a 79,80 após 90 dias.

A variação no parâmetro $a^{\star}$, relacionado ao escurecimento enzimático das maçãs, está representada na Tabela 4 , em função do tempo de armazenamento a $10{ }^{\circ} \mathrm{C}$. 


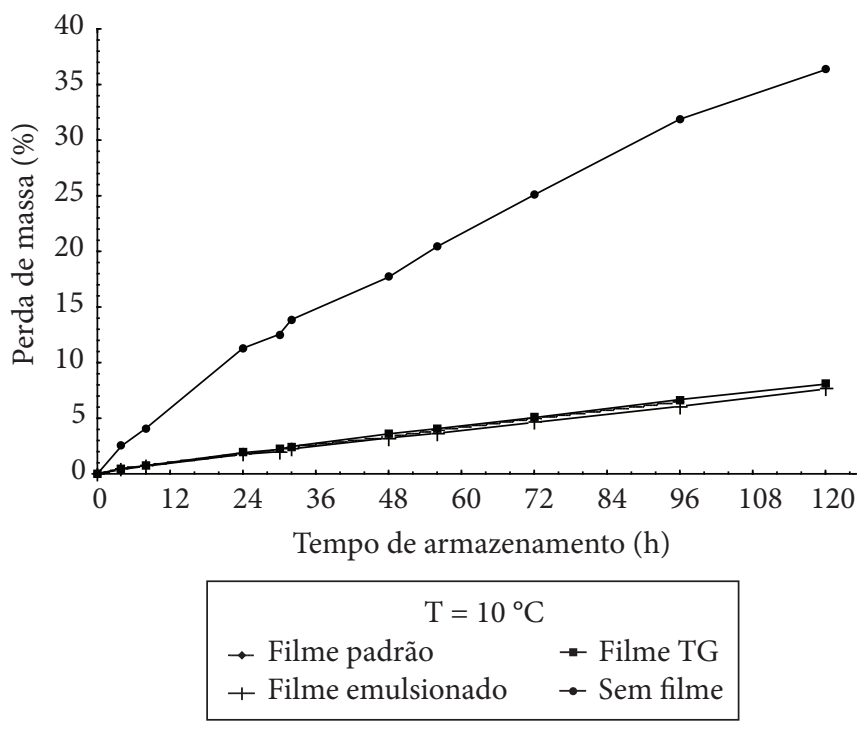

Figura 4. Perda de massa das amostras de maçã acondicionadas a $10{ }^{\circ} \mathrm{C}$ em sistema aberto e fechado com filmes proteicos de soro de leite: padrão, emulsionado e modificado enzimaticamente.

Em todos os sistemas, os valores de $\mathrm{a}^{*}$ aumentaram gradualmente com o tempo, indicando a ocorrência do escurecimento enzimático, sendo mais acentuado em sistema aberto, onde as amostras de maçã estão em contato direto com o ar ambiente (Figura 54). Baldwin et al. (1996) também não conseguiram evitar o escurecimento com a aplicação de cobertura de carboximetilcelulose em fatias de maçã acondicionadas em sacos plásticos a $4{ }^{\circ} \mathrm{C}$, observando que o escurecimento foi retardado após a imersão em antioxidantes, acidulantes e conservantes.

$\mathrm{Na}$ embalagem em atmosfera modificada observou-se um menor escurecimento das amostras de maçã em todo o período de armazenamento, quando comparada às embalagens sem injeção de nitrogênio, podendo-se considerar a redução da concentração inicial de oxigênio uma técnica favorável. Nicoli et al. (1994) concluíram que a embalagem plástica em atmosfera modificada $\left(\mathrm{N}_{2} / \mathrm{CO}_{2}\right)$ reduziu a concentração de oxigênio e foi efetiva na prevenção da reação de escurecimento enzimático em fatias de maçã por no mínimo 9 dias de estocagem. Em pedaços de manga cobertos com filmes de polissacarídeo e cera de carnaúba, a permeância de oxigênio foi menor em relação à do controle (sem cobertura), mas com diferenças pequenas (BALDWIN et al., 1999).

O escurecimento enzimático das maçãs, representado pelo parâmetro $\mathrm{a}^{*}$ encontrado após 24 horas de armazenamento a $10^{\circ} \mathrm{C}$ em sistema aberto foi atingido neste mesmo período em sistema fechado com filmes padrão, em 96 horas com filmes emulsionados. E em filmes modificados com a enzima, este parâmetro aumentou até 8 horas, mantendo-se constante até o final. Por estes resultados, concluiu-se que os filmes atuaram como barreira ao oxigênio, prolongando o tempo de armazenamento das amostras de maçã acondicionadas a frio, evidenciando a

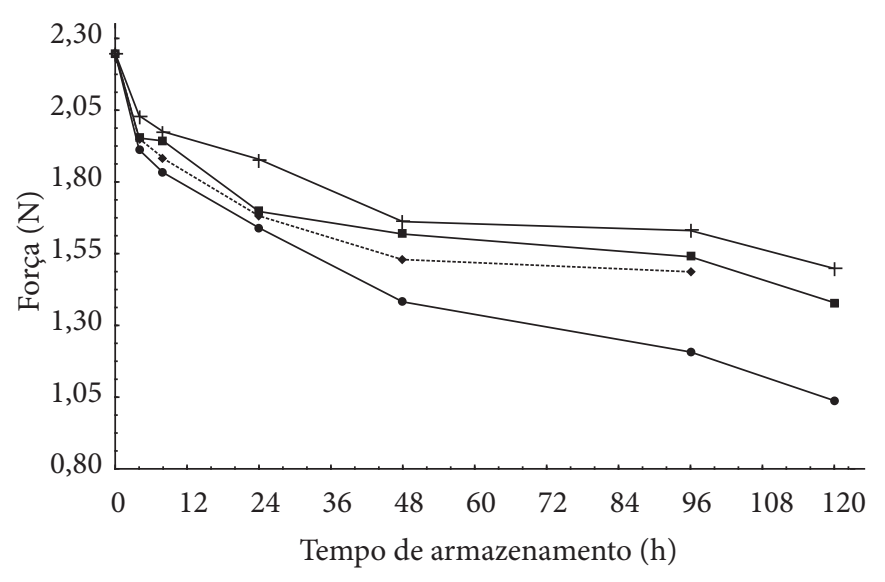

$$
\begin{array}{|l|c|}
\hline \multicolumn{2}{|c|}{\mathrm{T}=10^{\circ} \mathrm{C}} \\
\rightarrow \text { Filme padrão } & \rightarrow \text { Filme TG } \\
+ \text { Filme emulsionado } & \rightarrow \text { Sem filme }
\end{array}
$$

Figura 5. Força na perfuração nas amostras de maçã acondicionadas em sistema aberto (sem filme) e fechado com filmes proteicos de soro de leite (padrão, emulsionado e modificado enzimaticamente) em função do tempo de armazenamento a $10^{\circ} \mathrm{C}$.

estrutura da matriz filmogênica, apresentando exposição de grupos polares, que favorecem a barreira a substâncias não polares, tais como oxigênio e alguns compostos aromáticos. Deve-se ressaltar que a embalagem de frutas e vegetais frescos requer uma transferência mínima de $\mathrm{O}_{2}$ e $\mathrm{CO}_{2}$ para manter a respiração em taxas reduzidas.

Os pedaços de maçã tenderam a uma coloração amarela mais forte nas primeiras 8 horas de acondicionamento, representada pelo índice de croma $\mathrm{b}^{*}$, mantendo-se constante até o final do armazenamento, em todos os tipos de embalagem aplicados. Mas, não apresentou relação com o tempo de armazenamento e tipo de tratamento (com ou sem a injeção de nitrogênio).

A característica de barreira a gases dos filmes proteicos de soro de leite foi mais bem representada pelos parâmetros de cor $\mathrm{a}^{*} \mathrm{eL}^{*}$, quando relacionada ao comportamento de escurecimento enzimático das amostras de maçã acondicionadas neste sistema de embalagem, nas diferentes condições de armazenamento. Confirmou-se a afirmação de Sapers (1993); o escurecimento enzimático em maçãs cortadas pode ser monitorado pela medida das mudanças nos índice de luminosidade $\mathrm{L}^{*} \mathrm{e} \mathrm{a}^{*}$.

\section{Conclusões}

Filmes proteicos de soro de leite apresentaram uma barreira à umidade e a gases moderada quando comparados ao armazenamento em sistema aberto (sem tampa) nas condições de $25{ }^{\circ} \mathrm{C}$ e $75 \%$ de umidade relativa e $10{ }^{\circ} \mathrm{C}$, mantendo a sua integridade até o final do armazenamento, indicando um grande potencial para aplicação como embalagem, evidenciando as características de permeabilidade ao vapor d'água e gases e as propriedades mecânicas. 
Tabela 4. Índice de croma ( $\mathrm{a}^{*} \pm$ desvio padrão) das amostras de maçã acondicionadas em sistema aberto e fechado com filmes protéicos (padrão (FP), emulsionado (FEM) e modificado enzimaticamente $(\mathrm{FTG})$ ) $\operatorname{com}\left(\mathrm{N}_{2}\right)$ e sem $\left(\right.$ ar) a injeção do gás nitrogênio, na $\mathrm{T}=10^{\circ} \mathrm{C}$.

\begin{tabular}{|c|c|c|c|c|c|c|c|}
\hline \multicolumn{2}{|c|}{ Sistema de embalagem } & \multicolumn{6}{|c|}{$\mathrm{a}^{*}$} \\
\hline & & \multicolumn{6}{|c|}{ Tempo (h) } \\
\hline & & 0 & 4 & 8 & 24 & 48 & 96 \\
\hline \multirow[t]{2}{*}{ FP } & ar & $1,29 \pm 0,07^{\mathrm{n}}$ & $7,47 \pm 0,20^{\text {ghij }}$ & $7,96 \pm 0,37^{\text {efghi }}$ & $9,27 \pm 0,70^{\mathrm{bc}}$ & $9,30 \pm 0,05^{b}$ & - \\
\hline & $\mathrm{N}_{2}$ & $1,29 \pm 0,07^{\mathrm{n}}$ & $6,34 \pm 0,29^{\operatorname{lm}}$ & $7,31 \pm 0,97^{\mathrm{ijk}}$ & $7,02 \pm 0,82^{\mathrm{jkl}}$ & $7,79 \pm 0,50^{\text {efghi }}$ & - \\
\hline \multirow[t]{2}{*}{ FEM } & ar & $1,20 \pm 0,29^{\circ}$ & $6,16 \pm 0,65^{\mathrm{m}}$ & $8,45 \pm 0,71^{\mathrm{de}}$ & $8,29 \pm 0,36^{\mathrm{def}}$ & $8,45 \pm 0,06^{\text {de }}$ & $9,87 \pm 0,28^{\mathrm{ab}}$ \\
\hline & $\mathrm{N}_{2}$ & $1,20 \pm 0,29^{\mathrm{n}}$ & $6,64 \pm 0,42^{\mathrm{klm}}$ & $7,71 \pm 0,11^{\text {fghij }}$ & $7,86 \pm 0,54^{\text {ghij }}$ & $7,54 \pm 0,26^{\text {fghi }}$ & $8,49 \pm 0,39^{\mathrm{de}}$ \\
\hline \multicolumn{2}{|c|}{ Sem Filme } & $1,19 \pm 0,02^{\mathrm{n}}$ & $7,81 \pm 0,43^{\text {efghi }}$ & $8,58 \pm 0,28^{\mathrm{cd}}$ & $9,39 \pm 0,66^{\mathrm{b}}$ & $10,53 \pm 0,51^{\mathrm{a}}$ & $10,15 \pm 0,30^{\mathrm{a}}$ \\
\hline
\end{tabular}

a, b, c, d, e, f, g, h, i, j, k, l, m, n - diferenças significativas entre as médias ( $\mathrm{p}<0,05)$ calculadas através do método de Tukey pelo programa computacional SAS (SAS Institute Inc., Cary, N.C., USA).

Em relação à migração de umidade (perda de massa, teor de umidade e mudança de textura), a aplicação dos filmes proteicos de soro de leite acondicionados a $25^{\circ} \mathrm{C}$ e $75 \%$ de umidade relativa apresentou diferenças em até 40 horas no tempo de armazenamento, estando diretamente relacionada a permeabilidade ao vapor d'água dos filmes. Na mesma proporção quanto ao escurecimento enzimático em relação ao do sistema aberto. $\mathrm{O}$ armazenamento em temperatura mais baixa $\left(10^{\circ} \mathrm{C}\right)$ apresentou diferenças nos valores em até 80 horas no tempo de armazenamento quanto à perda de massa, e o escurecimento apresentou melhores valores de $\mathrm{a}^{*}$ com filmes modificados com transglutaminase.

O escurecimento enzimático das maçãs foi evidenciado pelo índice de croma $\mathrm{a}^{*}$, que aumentou em função do tempo de armazenamento, apresentando diferença em relação ao das amostras acondicionadas em atmosfera modificada com gás $\mathrm{N}_{2}$.

\section{Agradecimentos}

À FAPESP pelo suporte financeiro da pesquisa e à FEA Faculdade de Engenharia de Alimentos - UNICAMP, local onde foi desenvolvida a pesquisa.

\section{Referências bibliográficas}

AKESON, W. R.; STAHMANN, M. A. A pepsin pancreatin digest index of protein quality evaluation. Journal of Nutrition, v. 83, n. 1, p. 257-261, 1964.

ASSOCIATION OF OFFICIAL ANALYTICAL CHEMISTS - AOAC. Official Methods of analysis: Food composition, additives, natural contaminants. 16 ed. Maryland, 1997.

AMERICAN SOCIETY FOR TESTING AND MATERIALS - ASTM. Standard Test Methods for determining gas permeability characteristics of plastic film and sheeting. ASTM Book of Standards. Philadelphia, 1995.

AVENA-BUSTILLOS, R. J.; KROCHTA, J. M. Water vapor permeability of caseinate-based edible films as affected by $\mathrm{pH}$, calcium crosslinking and lipid content. Journal of Food Science, v. 58, n. 4, p. 904-907, 1993.

BALDWIN, E. A. et al. Effect of two edible coatings with different permeability characteristics on mango (Mangifera indica L.) ripening during storage. Postharvest Biology and Technology, v. 17, n. 3, p. 215-226, 1999.

BALDWIN, E. A. et al. Improving storage life of cut apple and potato with edible coating. Postharvest Biology and Technology, v. 9, n. 2, p. 151-163, 1996.

CANNARSI, M. et al. Use of biodegradable: films for fresh cut beef steaks packaging. Meat Science, v. 70, n. 2, p. 259-265, 2005.

CHEN, H. Functional properties and applications of edible films made of milk proteins. Journal of Dairy Science, v. 78, n. 11, p. 2563-2583, 1995.

DICKINSON, E. Enzymic crosslinking as a tool for food colloid rheology control and interfacial stabilization. Trends in Food Science \& Technology, v. 8, n. 10, p. 334-339, 1997.

FÆRGEMAND, M.; MURRAY, B.; DICKINSON, E. Cross-linking of milk proteins with transglutaminase at the oil-water interface. Journal of Agricultural Food Chemistry, v. 45, n. 7, p. 2514-2519, 1997.

FLANAGAN, J.; GUNNING, Y.; FITZGERALD, R. J. Effect of crosslinking with transglutaminase on the heat stability and some functional characteristics of sodium caseinate. Food Research International, v. 36, n. 3, p. 267-274, 2003.

GALLO, J. A. Q. et al. Lipid hydrophobicity, physical state and distribuition effects on the properties of emulsion-based edible films. Journal of Membrane Science, v. 180, n. 8, p. 37-46, 2000.

HERSHKO, V.; NUSSINOVITCH, A. Physical properties of alginatecoated onion (Allium cepa) skin. Food Hydrocolloids, v. 12, n. 2, p. 195-202, 1998.

KIM, S. J.; USTUNOL, Z. Sensory attributes of whey protein isolate and candellila wax emulsion edible films. Journal of Food Science, v. 66, n. 6, p. 909-911, 2001.

KING, A. D.; BOLIN, H. R. Physiological and microbiological storage stability of minimally processed fruits and vegetables. Food Technology, v. 43, n. 2, p. 132-139, 1989.

LERDTHANANGKUL, S.; KROCHTA, J. M. Edible coatings effects on postharvest quality of green bell peppers. Journal of Food Science, v. 61, n. 1, p. 176-179, 1996.

LI, P.; BARTH, M. M. Impact of edible coatings on nutritional and physiological changes in lightly-processed carrots. Postharvest Biology and Technology, v. 14, n. 1, p. 51-60, 1998.

MAHMOUD, R.; SAVELLO, P. A Mechanical properties and water vapor transferability through whey protein films. Journal of Dairy Science, v. 75, n. 11, p. 942-946, 1992. 
MATÉ, J. I.; KROCHTA, J. M. Oxygen uptake model for uncoated and coated peanuts. Journal of Food Engineering, v. 35, n. 3, p. 299-312, 1998.

MATÉ, J. I.; KROCHTA, J. M. Whey protein coating effect on oxygen uptake of dry roasted peanuts. Journal of Food Science, v. 61, n. 6, p. 1202-1206, 1996.

McHUGH, T. H.; KROCHTA, J. M. Dispersed phase particle size effects on water vapor permeability of whey protein-beeswax edible emulsion films Journal of Food Processing and Preservation, v. 18, n. 3, p. 173-188, 1994.

McHUGH, T. H.; SENESI, E. Apple wraps: a novel method to improve the quality and extend the shelf life of fresh-cut apples. Journal of Food Science, v. 65, n. 3, p. 480-485, 2000.

MIN, S.; KROCHTA, J. M. Ascorbic Acid-Containing Whey Protein Film Coatings for Control of oxidation. Journal of Agricultural Food Chemistry, v. 55, n. 8, p. 2964-2969, 2008.

MORR, C. V.; HA, Y. W. Whey protein concentrates and isolates: processing and functional properties. Critical Reviews in Food Science and Nutrition, v. 33, n. 6, p. 431-476, 1993.

MURATORE, G. et al. The influence of using biodegradable packaging .films on the quality decay kinetic of plum tomato PomodorinoDatterino. Journal of Food Engineering, v. 67, n. 4, p. 393-399, 2005.

NICOLI, M. C.; ANESE, M.; SEVERINI, C. Combined effects in preventing enzymatic browning reactions in minimally processed fruit. Journal of Food Quality, v. 17, n. 3, p. 221-229, 1994.

NUSSINOVITCH, A.; HERSHKO, V. Gellan and alginate vegetable coatings. Carbohydrate Polymers, v. 30, n. 2-3, p. 185-192, 1996.

OZDEMIR, M.; FLOROS, J. D. Optimization of edible whey protein films containing preservatives for mechanical and optical properties. Journal of Food Engineering, v. 84, n. 1, p. 116-133, 2008.
SAPERS, G. M. Browning of foods: control by sulfites, antioxidants and other means. Food Technology, v. 47, n. 10, p. 74-84, 1993.

SAPRU, V.; LABUZA, T. P. Dispersed phase concentration effect on water vapor permeability in composite methyl cellulose-stearic acid edible films. Journal of Food Processing and Preservation, v. 18, n. 5, p. 359-368, 1994.

SHEWFELT, R. L. Quality of minimally processed fruits and vegetables. Journal of Food Quality, v. 10, n. 3, p. 143-156, 1987.

SOLIVA-FORTUNY, R. C. et al. Browning evaluation of ready-to-eat apples as affected by modified atmosphere packaging. Journal of Agricultural and Food Chemistry, v. 49, n. 8, p. 3685-3690, 2001 .

SZCZESNIAK, A. S. Effect of storage on texture. In: TAUB, I. A.; SINGH, R. P. (Eds.). Food Storage stability. Boca Raton: CRC Press, 1998. p. 191-244.

THARANATHAN, R. N. Biodegradable films and composite coatings: past, present and future. Trends in Food Science and Technology, v. 14, n. 3, p. 71-78, 2003.

TROFIMOVA, D.; JONGH, H. H. J. Modification of beta-lactoglobulin by oligofructose: impact on protein adsorption at the air water interface. Langmuir, v. 20, n. 13, p. 5544-5552, 2004.

VICENTINI, N. M.; CASTRO, T. M. R.; CEREDA, M. P. Influência de películas de fécula de mandioca na qualidade pós-colheita de frutos de pimentão (Capsicum annum L.). Ciência e Tecnologia de Alimentos, v. 19, n. 1, p. 127-130, 1999.

YANG, L.; PAULSON, A. T. Mechanical and water vapour barriers properties of edible gellan films. Food Research International, v. 33, n. 7 , p. $563-570,2000$ b. 